\title{
Two
}

\section{THE LEVELS OF VALUE LANGUAGE}

The greatest art in theoretical and practical life consists in changing the problem into a postulate.' Goethe

At present, no language of value exists in the sense in which mathematics or, to speak with Tobias Dantzig, number, is the language of science. ${ }^{2}$ Rather, a variety of value languages exists, and it may well be doubted whether there is any systematic relationship between them at all. Yet, if the scale of axiological cognition is more than a metaphor, there must be a way in which we can systematically interrelate the theories mentioned. That is to say, the higher they are on the scale, the higher they must be in empirical and systematic import. In this chapter, I will further refine the scale and develop it into a methodological structure so that, rather than measuring value theories, these theories become embedded in it as their matrix. I develop, in other words, the scale into a theory of value theories - a meta-axiology. From an analysis of what value theories are, I now proceed to a statement of what they ought to be. In such an endeavor, some theories that have no value for the cognitive understanding of value, such as the non-cognitivist, will fall by the wayside. The absolute zero point of the scale will become what it is —of zero importance for value. Theories at the other end of the scale will assume a greater importance for value; they will be more fully examined, and their nature as science will be elaborated.

The language of science is multi-dimensional; it rises from simple description of factual situations through generalizations in empirical sciences to the mathematical accounts of reality in fully developed sciences, such as physics and astronomy. Each layer of language represents a different level of analysis. On level zero is the undescribed situation. On level one is the empirical language that describes the situation, the language of fact. On level two is the generalized language that analyzes the empirical language. Thus, a physician telling colleagues about the symptoms that a patient has, as described in everyday language, relates them in an entirely different language bristling with general concepts, mostly of Latin and Greek origin, of which the patient knows nothing. The physician's language is on the second level; it restates, in terms of generalizations, the empirical language and refers to it. There is no third-level medical language, unless it be Greek or Latin itself as a self-contained system containing the medical terms. But these languages, while containing these terms, lack the relations between the terms that correspond to the relations between the referents of the terms in reality. If the symptoms of human sicknesses were related to one another like the grammar of their terms, medicine would be an "exact" science. Whereas physiological and pathological phenomena, so far, have eluded systematization, physical, astronomical, and other material phenomena have not. The physicist, in addition to learning to observe and relate empiri- 
cal situations, must learn a language, namely mathematics, that is empirically foreign to him - people don't speak algebra - and which, as such, has nothing to do with physics. Mathematics is a purely formal system of relationships which happen in part to correspond to relationships between physical events. Experiments and observations sometimes confirm that physical events, thought of as standing in the same relationship to one another as the numbers of certain equations, actually do stand in such a relationship. The numbers then stand for classes of such events signified by certain variables of which the corresponding events are values, not in a formal, but in the spatio-temporal context of the science in question.

To take a classic and simple example, the purely mathematical relation $\mathrm{x}^{2} / \mathrm{y}^{3}$ $=1$ was interpreted by Johannes Kepler as signifying $\mathrm{T}^{2} / \mathrm{D}^{3}=1$, where $\mathrm{T}$ is the time of revolution around the sun and $\mathrm{D}$ the mean distance of a planet from the sun. The second equation is an application or value in the sense mentioned of the first. These values of the pure numbers arise by interpreting the pure number in terms of certain dimensions - space, time, and weight. They thus become not pure but dimensional variables whose values, in turn, are the actual quantities for the individual planets, for example $T=.241$ earth-years and $D=.387$ earth-distances for Mercury. They are the actual measurements of the physical phenomena. Cube, square, and division as such have nothing to do with planetary motion. Yet, once the normativity of the purely formal relation for the physical phenomenon is found, the whole complex of related formal configurations opens up. The above equation led to Newtonian and finally to Einsteinian-Riemannian equations of great complexity and scope.

As guiding physical research, experimentation, and prediction, the mathematical pattern may be regarded not merely as referring to the physical realm but as normative for and creative of it. In being a self-contained formal system, mathematics is a storehouse of conceptual relations from which physicist choose when their empirical description of the situation and the generalization of this description have reached the point at which even technical language is incapable of leading them on to more precise accounts of the interrelationship between the generalized concepts. At this point imagination must leave the empirical and its abstractions, leap into the realm of the purely formal, surrender its own spontaneity to the machinery of the calculus, and accept its results without immediately knowing what they empirically mean. In this sense, for Galileo, mathematics was the logic of discovery. ${ }^{3}$

Scientific language, thus, consists of three levels: the empirical (which describes situations), the general or technical (which refers to the empirical), and the normative or formal (which is self-contained, independent of any empirical situation, and capable of analyzing both the empirical and the general language in its own terms).

The world of value is at least as complex as the world of facts. There is no reason why it should not also require a hierarchy of languages. ${ }^{4}$ If value exists in the world, then it must be in situations, either in objects or in subjects, or in 
relations between them, either in overt actions or covert motives, in ordering thoughts, or in the language itself of situational agents. Wherever and whatever value may be, it must be somewhere somehow and discoverable either by or in thought, that is, language. Taking our clue from the language of science, there ought to be on the first level an empirical language which describes situations from the point of view of value, whatever this may be. Since, at this level, there is no norm defining the value realm systematically, that is, in terms of an independent conceptual scheme, any assertion as to what constitutes the value character of a situation may pass - pleasure, choice, preference, interests, satisfaction, approval, purpose, harmony, utility, fittingness, growth, sympathy, or whatever else. Also, any statement as to where value is to be found will be acceptable - in the object, the subject, the situation as a whole-and where in the object or the subject-outside, inside, in motives, in attitudes, in thoughts, in language, and so on. But none of these terms has systematic import. Depending on the ingenuity of the constructor, empirical descriptions may be elaborated - and elaborate - but will stand beside each other, like trees in a forest, with the wood itself not visible. Some of these languages may not look empirical, for example, when they analyze language itself, namely the language spoken in the situation. This language is like all other elements mentioned, a situational constituent. Thus, when " $x$ is good" is asserted to mean "I like $x$," it is asserted that whenever a person in a situation says " $x$ is good" he or she means "I like $x$." This analysis of what people in situations say and how value is found in what they say is still an empirical, that is, a first-level, analysis of the situation.

The situation itself has levels, beginning with the purely factual floor on which overt actions and expressions occur, level zero. A sub-situational level of covert motives and attitudes gives rise to these actions and expressions. On a supra-situational level are judgments about the situation. These may be called level minus one-half and level one-half, respectively. Empirical analysis may shuttle back and forth among these situational levels, analyze the facticity of a situation, then delve under the surface for the corresponding motives or rise above it for the corresponding judgments, and it may interrelate all three. But withal it is empirical analysis and on the first level; or, rather, it ranges from level one-half, the analysis of situational motives on level minus one-half, to level one-and-a-half, the analysis of situational judgments on level one-half, with level one, the analysis of the overt facts of the situation itself, in the middle. The situational analyst may glide down into level one-half, speaking as an agent in the situation itself rather than as its analyst on level one.

Second-level value language analyzes and elaborates concepts, including those of first-level language. It is a kind of meta-language to level one. Thus, out of the value-fact of purpose may be developed a language of "purposive values" or a full-fledged system of teleology, out of the value-fact of pleasure a "hedonic calculus" or a "hedonistic axiology," out of the value-fact of interest a "general theory of value," out of that of choice a "judgmental function," and 
out of that of preference a "logic of preference." Out of situational value language, with emphasis on the subjective matrix, may be developed an emotive theory of language or, with emphasis on the sign character of language, a semantic interpretation of value. There may be subjective, objective, or relational value theories. In short, every situational element may serve as foundation for an empirically systematized value language. Each of these represents another empirical analysis, and axiologists ought to recognize in the various situational elements mentioned the corresponding literature built upon them. Although such languages are more general than first-level empirical languages, they share with them the arbitrariness of the determination as to what constitutes value.

On the third level, finally, we ought to have independent formal structures of systematic relationships capable of defining lower level concepts in systematic terms and ordering the total realm of value — ethical, aesthetic, psychological, social, religious - in a way similar to that in which mathematics orders the realm of facts. There is, so far, one such formal axiology, but any number is theoretically possible.

A formal axiology need not be constructed in explicitly logical terms; it could be established in semiotic or mathematical terms - either of Euclidean geometry as in Spinoza, or non-Euclidean, as in Henry Lanz ${ }^{5}$-or in terms of any other system. No matter what the system, it must, in the last resort, be based on formal logic; and its axiom must be an identification between value and a systemic element. It must give "value," as axiomatically defined, both systematic and empirical import. It must be isomorphic with the realm of value phenomena. It must be a formal system of axiology whose variables- "good," "bad," "ought," and so on-are applicable to specific value dimensions - ethics, aesthetics, economics, psychology, sociology, religion-where they appear as "values"-_"moral good," "beautiful," "expensive," "satisfactory," "efficient," "holy," and the like-which in turn serve as dimensional variables for certain specific value phenomena, just as do " $D$ " and " $T$ " in Kepler's third law for specific physical phenomena.

\section{First Level: Empirical Value Language}

Empirical value language is the description of value experience and value phenomena in terms of everyday language. This is a large part of what is traditionally called "Ethics." It suffers from two shortcomings: (l) the indefiniteness of the empirical realm of morality, and (2) the vagueness and arbitrariness of the empirical concepts abstracted from that realm.

\section{A. Indefiniteness of the Moral Realm}

Since, at this stage, we have no principles for defining the realm of morality, it is impossible to decide what are and what are not moral phenomena, and what 
are the grounds on which any phenomena should be called moral and thus be assigned to the subject-matter of ethics rather than that of some other discipline. If we think of situations and ask ourselves whether or not they are moral situations, we are at a loss for criteria by which to guide our judgment. Think, for example, of a child snatching a piece of candy behind his mother's back. Then think of Hitler declaring war on America. Somehow, we feel, both are moral situations. But we cannot put our finger on the differentia that they have in common. Equally divergent and yet similar situations are endless. Here is Jesus hanging on the cross and forgiving his enemies, and here is a fetishist who loves buttons. Here is the sign saying "Lidice," which is all that is left of a Czech village, and here is a stop sign. Here is a soldier shooting the legs off an enemy, and here a medic rushing to restitute or restore these legs to that same enemy. Here is a parliament discussing public housing, and here a rat catcher laying poison for the rats. Here is Wolfgang Mozart, a most lovable man, and here Don Giovanni, his creation, the epitome of satanic wickedness. Are any of these actual or fictional situations moral, belonging to ethics? If so, what do they have in common and how are they interrelated? What is their relationship to value in general? How about other situations that have to do with value but do not belong to ethics - the price of a cow, the pricelessness of a Rembrandt, the love of flag and fatherland, the love of God, the beauty of a mathematical proof, and the justice of a trial? All these things, we vaguely feel, have to do with value, but neither our language nor our experience seems to supply the connection. What has the price of a button in common with the valuation of the fetishist, and both with Lidice or the love of God? Merely mentioning all these in the same sentence seems a juxtaposition so arbitrary as to be frivolous. To find a connection in the variety of all these and untold other phenomena-moral, economic, metaphysical, religious, aesthetic (all having to do with value)-we cannot, it seems, remain on the level of empirical language and its concepts.

\section{B. Vagueness and Arbitrariness of Empirical Value Concepts.}

The second shortcoming of first-level analysis is the vagueness and arbitrariness of the empirical concepts used in it. Since these concepts are abstracted from the infinite and indefinite variety of phenomena, they cannot contain principles for defining the empirical realm or any of its sections. All they can do is, in a more or less arbitrary manner, classify and distinguish the phenomena. Even if someone would sharpen this terminology to the highest possible degree (as has been done by Albert L. Hilliard for hedonism ${ }^{6}$ ), any system built on these concepts would suffer a double inadequacy. The enterprise of systematization on the empirical level is inherently arbitrary and possible only, as Kant has shown, on the assumption of an inherent logical orderliness of empirical nature, designed especially for the human mind - the assumption "that nature specifies its universal laws into empirical laws in accordance with the forms of a logical system on 
behalf of the faculty of judgment." This assumption of natural purposiveness alone gives the possibility of empirical system, "the conformity to law of the contingent as such." Granted the justification of such an assumption, either the Kantian or some other, a second and even graver difficulty remains. No ground justifies why the moral realm should be ordered in terms of one empirical concept rather than another. There is no ground why it should be in terms of pleasure rather than pain (think of William James's ethical principle of greatest resistance, or Arthur Schopenhauer's resignation of the will), or of reason rather than unreason (think of Thrasymachus and Friedrich Nietzsche), or of happiness rather than unhappiness (think of the saintly ecstasies of martyrs), or of virtue rather than vice (think of Niccolò Machiavelli or imagine a future theologian going the Niebuhrian road all the way and declaring that, since man is originally and irretrievably sinful, he may just as well make the best of it). This is in line with the famous limerick,

At Ipswich, when Niebuhr had quit it

A young man said: "Ah, now I've hit it.

Since nothing is right

I shall go out tonight

And find the best sin and commit it."

No ground mandates that or explains why a system of morals should be based on any one of these concepts, or on any of the other concepts proposed in empirical ethics: utility, self-realization, fittingness, loyalty, sympathy, growth, process, interest, satisfaction, choice, obligation, approval, agreement, or any combination of such concepts. "Obligation" is either a naturalistic concept or else, when called "moral," begs the question with which we are concerned, namely, What is moral? Any system built on any such concept or combination of concepts is contingent, empirical, and naturalistic. However we may call it, it is on the first level of analysis. No amount of mixing of such concepts-not even occasional dashes of "ought," particularly when used synonymously with one of these concepts, such as "obligation" - can perform the magic of transmuting the mixture into a higher species. It remains on the first level, no matter what the label on the retort; even if it reads "non-natural," the content is still natural.

In addition to the concepts so far used in ethics, there is practically no empirical concept having to do with human situations that could not be added to the list. Not only could someone write an ethics of honesty, integrity, kindness, generosity, slyness, superiority, humility, and similar obviously ethical concepts, but also of seemingly non-ethical concepts, such as race, health, hunger, instinct, intuition, and the like; indeed, a program could be written for yet unwritten kinds of ethics. But no one could ever come to the end of such a program, let alone write the infinity of possible ethical systems. All these sys- 
tems would be, and are-insofar as they have been written-arbitrary and extend one aspect of moral reality over all the rest. They abstract one aspect of empirical reality and hypostatize it at the cost of all the rest.

This hypostatization may be empirical in two senses. First, it may be empirical in the sense just discussed, the extension of one aspect of reality over all the rest, a fallacy of systematic procedure that may be compared to the fallacy of the illicit major in the syllogism. Or, secondly, it may consist in the extension of this one aspect not merely over all empirical reality but over all reality, both empirical and non-empirical. In this case the aspect assumes the features of a metaphysical or ontological system. But such hypostatization, by fiat of the ethicist, delivers the empirical from the clutches of the natural as little as the "abracadabra" of the medicine-man delivers, say, the native of the Zambezi from elephantiasis. On the contrary, the arbitrary features of the empirical become in this procedure enlarged to monstrous dimensions, indeed, to infinity. G. E. Moore makes the following comments about this occurrence:

The region of the incompletely known is the favorite abode of a metaphysical monstrosity. In plain language, where facts are not completely understood, some short-sighted metaphysical theory is generally introduced as affording an easy road past the difficulties which stand in the way of thorough investigation. ${ }^{10}$

The discrepancy between the system's claim to validity and its justification is in the proportion of infinity to zero, a proportion which is, even mathematically, undefined and strictly senseless. But it gives the ethicist a measure of self-assurance that no naturalistic system can match, simply because naturalism's arbitrary character is written on its face, whereas in the metaphysical system this same arbitrariness is submerged in the ethicist's unconscious and thus, like any complex, appears in exaggerated behavior. Metaphysical ethicists when, as is so often the case, completely uncritical of their procedure, go God one better, so to speak: they do not merely create an earth out of heaven, but a heaven out of earth. In this heaven they find laid up the treasure they supposedly cannot find in this vale of despair, and they are entirely unaware of the fact that the whole equipment of his heaven they first had to lug up from below. The same is true of an ideology."

For this reason all ethical writers on higher levels of analysis have classified metaphysical and ontological value systems alongside the empirical-such as Kant in his equation of empirical and metaphysical dogmatism, G. E. Moore in his extension of the naturalistic fallacy to metaphysical ethics, Jean-Paul Sartre in his characterization of mauvaise foi as including reliance on all systems (whether empirical or metaphysical) which through the mirage of false security seduce people to abandon the onerous job of becoming themselves and present them with an excuse for resigning from humanity. In the last instance, 
the lack of definition in empirical ethics leads to lack of definition in the ethical experience, the agents of ethics, human beings themselves. An interesting verification of the essential identity between naturalistic and metaphysical dogmatism is the heavy traffic over the border of the two realms, for example, of converted communists into Catholicism and converted Catholics into communism.

Through the mixture of naturalistic methodology with supernatural sanctions, the metaphysical ethicist becomes a preacher rather than a thinker and thus, to this degree, gives up the philosophical enterprise. Unable to transcend the empirical, yet loudly protesting that they do, their arguments, far from being sublime, are earthy, and often crudely so; they either try to scare or to bribe us into morality. Instead of illuminating us from above they radiate from within the empirical realms, and the result is more often a burn than an elucidation. This is true of some of our present prophets as well as of many of the past. H. A. Prichard made these comments:

We have only to consider the history of Moral Philosophy. To take obvious instances, Plato, Butler, Hutcheson, Paley, Mill, each in his own way seeks at bottom to convince the individual that he ought to act in so-called moral ways by showing that to do so will really be for his happiness. Plato is perhaps the most significant instance, because of all philosophers, he is the one to whom we are least willing to ascribe a mistake on such matters, and a mistake on his part would be evidence of the deep-rootedness of the tendency to make it....Plato really justifies morality by its profitableness. ${ }^{12}$

Compare Schopenhauer's scathing remark on Kant who, after arguing sublimely for virtue as its own reward, then offers a sop to the honest servant in the form of happiness. The epistemological failure of this level of ethics appears, from the higher level, as a failure of ethics-not merely formal, but material: it makes the ethics unethical. Definition in ethics becomes an ethical demand, and a mistake in ethical thinking a failure in higher level morality.

Empirical concepts give no definition of the moral realm. They do so neither directly nor indirectly. It has sometimes been held that what I analyzepleasure, satisfaction, and the like - is indicative of the moral phenomenon: whenever a moral situation occurs it is accompanied by pleasure, satisfaction, and the like. This assumption can be given little credence as long an we are ignorant about the moral phenomenon itself. But even granted the correlation in question, an analysis of the accompanying phenomenon would only be as good as, say, an analysis of the weather by means of the thermometer. It would only catch one aspect of the reality in question A whole array of additional instruments is needed to catch more of its aspects, and even then no one could be sure to have caught the essence of the phenomenon itself. One would again be confronted with the old difficulty of arbitrariness. Why should a particular indicator of morality, say, pleasure, be more reliable and indicative than any 
other? Actually, it has never been shown why and in what respect and with what necessity - or even empirical causality-pleasure, satisfaction, and the like should accompany morality.

Empirical concepts not only give no definition, either directly or indirectly, of the moral phenomenon, but they cannot even themselves be precisely defined. Precise definition, by definition, is non-empirical. Therefore science, insofar as it uses precise concepts, is not generalization but invention-as was already held by Kant and has been reaffirmed in every generation since. ${ }^{13}$ Science consists, agreeing with Bertrand Russell, "largely of devices for inventing concepts having a greater degree of precision than is found in the concepts of everyday life." 14 The empirical concepts of ethics, therefore, cannot be precisely defined. They represent secondary qualities of moral phenomena and are as irrelevant to these phenomena themselves as are the secondary qualities of natural phenomena. I feel pleasure or I feel satisfaction, and scholars interested in ethics rather than psychology may well ask, "What of it?" But suppose they find these feelings relevant and give up their quest for precise definition; still they would never, even empirically, be able to define these concepts within the realm of ethics. To define satisfaction or pleasure, they would have to move into the fields of other empirical sciences such as psychology; and again they would be lost in a welter of confusing empirical determinations. The old dilemma would again present itself. Psychology, as little as any other empirical science, as Kant showed, is unable to supply principles for the definition of morality, let alone its normativity. Such principles can only be applied by analysis a priori, that is, by analysis of principles of thought itself.

But-and here we come to the perhaps most typically first-level attitudeinvestigation of the moral phenomenon and its principles a priori is in many cases decried from the outset as "a bad job," an unpromising and impossible task, on the simple assertion that moral phenomena are unanalyzable and hence to be known only by immediate intuition. This is not the position of G. E. Moore, who thought that moral phenomena, namely that to which the term "good" refers, are definable. Insofar as their goodness is indefinable, the necessity for intuition does not commit ethics to intuition. On the contrary, it commits it with so much more definiteness to correct principles. The supreme principle only, the axiom of scientific ethics, namely, goodness, is based on "intuition," but this intuition is not psychological but logical. In such cases, I commit myself to first-level analysis to discuss the moral experience exclusively in terms of my intuition and feelings. This attitude, if called philosophical, which seems a contradiction in terms, is of the same kind of philosophy as similar attitudes have been in the sciences where for a long time, words, supposedly ultimate, took the place of analysis. Thus, "intuitive" value has the same systematic position in axiology as phlogiston had in chemistry, or ether in physics, or, substance in dogmatic metaphysics. This renunciation of analysis in ethics has, from a metaethical point of view, an ethical aspect: renouncing ethical analysis on the basis of "intuition" is a failure of ethics itself; it prohibits the use of reason in ethics. This is 
as much a failure of ethics as was the building of natural or metaphysical systems, supposedly of ethics. What was achieved there, by building elaborate structures to prevent further inquiry, is achieved here in an even simpler way, by prohibiting intellectual curiosity from the outset and on principle. But, setting aside the specific meta-ethical implications of this attitude, and regarding it merely on its epistemological face value, the least that must be said is that the prohibition of analysis is not a fruitful basis for analysis.

In summary, then, first-level analysis is inadequate and should not be called ethics anymore, nor should it be taught as such, except historically. Rather, ethics should be called what we call second-level analysis or meta-ethics, as is already done by an increasing school of writers who follow G. E. Moore in his emphasis on the analysis of ethical propositions and ethical philosophies rather than of moral situations. Of note is the curious case of Bertrand Russell. He believes, with Moore, that the subject of ethics is "not practice but propositions about practice." Yet, he thinks that "whatever objectivity the concept (good) may possess is political rather than logical." In other words, an empirical foundation of ethics will give ethics more objectivity than a formal one. The "aim" of ethics, by which I mean its subjectmatter, is second-level analysis (propositions about practice). Yet, this aim can be reached better by first-level analysis (political concepts) than by third-level analysis (logic). No wonder Russell was never "quite satisfied with any view of ethics that I have been able to arrive at, and that is why I have abstained from writing again on the subject."'15

Let us now turn to the next level.

\section{Second Level: Analysis of Empirical Value Language}

By analysis of empirical value language I do not mean analysis of the language spoken in moral situations but analysis of the language used by ethicists about such situations. I mean analysis of empirical ethics or analysis of ethical language - the language used in ethics - as against the analysis of moral language - the language used in moral situations. The distinction will be important in the first type of analysis on the second level. A number of possible analyses are on this level, of which five seem the most important: pragmatic, semantic, logical, epistemological, and mathematical value analysis.

\section{A. Pragmatic Analysis}

By pragmatic analysis I mean an analysis of ethical language in terms of the situation in which that language occurs. This kind of analysis is, in one respect on a higher level than the empirical language that it analyzes; but in another important respect, it is on the same level. For what it analyzes is not really language, that is, language as a logical or semantical structure. Rather, it is language as a symptom of the situation, as a social instrument, ${ }^{16}$ as a tool of communication. It analyzes a certain aspect 
of the moral phenomenon itself, its language, and not the language about it-moral, not ethical language, in my terminology. In this respect, therefore, Charles L. Stevenson is incorrect in comparing the relation of his analysis to ethics with that of the relation of scientific method to science. ${ }^{17}$ If we compare levels of scientific and ethical language, the natural phenomenon, on zero level, would compare to the moral phenomenon; ethics, the first-level, to description of the natural phenomenon in empirical language; metaethics to science as formal analysis of first-level description, or science proper; and meta-meta-ethics to the formal superstructure of science, mainly mathematics. The account of the method of science is philosophy of science, or that discipline which describes the entire hierarchy. But Stevenson does not do this in the field of ethics. His main concern is to analyze moral language, that is, the language spoken in moral situations. Insofar as this language is regarded as an aspect of these situations, it is part of the moral phenomenon itself, that is, of the subject-matter of first-level ethics.

Stevenson's enterprise, then, in this respect, is first-level analysis, or what we called ethics. In another respect it is meta-ethics. Language, after all, is language and as such on a higher level than the non-symbolic elements of the situation. No matter what its pragmatic use, it is not empirical reality, but represents empirical reality-it is on a higher level than the situation in which it occurs. Or, to combine its involvement in the situation and its representing it, it is empirical reality itself on a higher level. Its analysis is on a higher level than the analysis of the situation in which it occurs. It is analysis of the empirical situation through the medium rather than in terms of one of its aspects. From this point of view pragmatic analysis may be called second-level analysis, but it is an analysis of language, not as such, but as a means for the analysis of the situation in which it occurs. This kind of analysis is a hybrid between the first and the second level; it analyzes the empirical situation through a specific analysis of its language. It is, so to speak, on level one-and-a-half.

Such analysis could conceivably examine the totality of moral reality if moral language were used as focus of the totality of that reality and not as focus of just one aspect of it. In moral language, moral reality could be found wholly contained, as the reality of a star is contained in the spectrum of its light. But to understand language in such a way and, through its analysis, to be able to analyze reality itself as moral, would presuppose a language that contains criteria for determining the moral character of a language. But this, we have seen, only a third-level language, a meta-metaethics, can do. Pragmatic analysis, as analysis of situational language, is, however, scarcely a meta-ethics. If this is so we are back at the old dilemma of arbitrariness, of having no principle whereby to define the moral phenomenon as such, which appears, this time, in the form of language. We are, also, back at the second difficulty, that of selecting one aspect of the moral phenomenon, again language, rather than any other, as representative of morality.

There is no ground why, of all the aspects of the moral situation, we should select just its language. Or, to state the matter conversely and thus lift it to the second level of analysis, why, of all things, should language be analyzed in terms of the 
situation in which it occurs? Why should it not rather be analyzed in terms in which language is usually analyzed, namely logic or, perhaps, semantics? If this question be answered by the pragmatist by saying that only in this way can he catch the moral characteristic of language, we would have to object that this is precisely the point to be established. Pragmatic analysis begs the question. Rather than establishing the moral character of a certain type of empirical language, it assumes this character and gears its analysis in accordance with this assumption. It thus overlooks that it suffers from the same shortcoming as all first-level analysis, namely, the inability to define its subject matter as moral. It cannot, then, use its lack of definitory ability as justification for its procedure. Rather, its procedure is equally arbitrary as first-level analysis, and a good case can be made for asserting that it is even more so. Charles L. Stevenson, for example, analyzes situational language in terms of a certain emotion of speakers, their quasi-imperative attitude of demanding approval. This is a very specific kind of emotion. But a situation is a complex structure of elements, of which this particular attitude is only a minute part.

To our first question, why language should be analyzed in terms of situation, we must now add a whole series of further questions. Supposing that language should be analyzed in terms of situation, why should situation be analyzed in terms of the speakers? Why not in terms of the environment of the situation as a whole? And if in terms of the speakers, why not in terms of their wills, or minds, or spirits? If we settle for their emotions, why in terms of one particular emotion rather than another? Finally, why should the result of this multiple arbitrary distillation be called morality? Pragmatic analysis is nothing but, by a roundabout way, a return to the empirical determinations of the first level, with emphasis on the aspects of approval and agreement rather than those of pleasure, satisfaction, and the like. We are thus, even though through a formal medium - which, however, the direction of the analysis in question deprives of its formality-back at the analysis of empirical data through empirical concepts. This analysis, not of the logic of what speakers say, but of the attitude in which they say it, is closer to psychology than to logic. Language is used as a kind of barometer or thermometer for what may lie behind it, and what may lie behind it is called the moral phenomenon. Granted that language is indicative of it, it is only one indication of it. We are back again at the first-level difficulty of needing additional indicators for morality, and to the many indicators of that level is now added one more, namely language. Thus we are one more step removed from the moral phenomenon: we use language as indicative of certain feelings and these feelings, in turn, as indicative of morality. We are not concerned with any a priori system of which the statements, judgments, utterances, propositions of approval and disapproval, or agreement and disagreement are an organic part, nor with any $a$ priori system of which the speakers are a part. At this point, we have no a priori principles by which to define the moral realm and have, in this all-important respect, not advanced beyond the first level.

Neither have we resolved the arbitrariness of selecting situational aspects; on the contrary, we may definitely be said to have increased it. Any number of other 
criteria for the analysis of situational language could be used. Instead of the speakers we could concentrate, as mentioned, on the environment, or on particular objects in it, or on the situation as a whole, and all this either statically or dynamically. There are at least three additional highly complex analytic possibilities, all of them pragmatic. Once we decide on a pragmatic analysis in terms of speakers, we can choose the speakers as a whole, or their minds, or their wills, or their spirits, or their emotions, or their sympathy, compassion, satisfaction, pleasure, happiness, inspiration, interest, and so on. These analyses would constitute an infinite number of possible pragmatic languages. If we choose just one of these possibilities, we can further specify certain kinds of emotions, pleasures, inspirations, satisfactions, and so on, as integrative principles, in an unending list. We do not have to choose the speakers' inner characteristics such as emotion, reason, or spirit. We can choose their outer characteristics such as their race or pedigree and develop a pragmatic ethics in terms of their titles, or their blue eyes and blond hair. Or we may choose their environmental situations, or aspects of them, and design an analysis of empirical value language in terms of the speakers' economic conditions. These and other pragmatic analyses have been designed and called ethics, sometimes with disastrous effects on humanity. The possibilities for pragmatic value analyses have no limits except those set by the ingenuity of philosophical minds. But all such analyses lack universality and $a$ priori principles that would give rules of transformation to the concepts of the language in terms of a higher, that is, non-empirical principle. For this reason, pragmatic value languages fall short of the standard that ought to rule a language of value comparable to that of science.

Ultimately, the reason for this is that the pragmatic endeavor, at least insofar as it is based on the positivistic conviction of the irrationality of value, is forced to return to the Humean dilemma of either trying to explain value by the empirical method supposedly of science, or else doing so in such a way that value will not lose its irrational nature, that is, will not be explained too much. Stevenson intends to apply rational analysis to the irrational or non-rational feature that is value, not for the purpose of clarifying and rationally explaining it, but to show even more clearly its irrationality. This to him is its ethical characteristic. He wants to apply the rational to the irrational, not in order to make it rational, but in order to deepen its irrationality. He wants to show, by a rational procedure, ethics as concerned with non-rational attitudes, rather than with rational beliefs.

If rational methods are used to analyze the non-rational, one of two things must happen. Either the analysis succeeds or it fails. If it succeeds, the non-rational, by virtue of being understood, loses its non-rational character and appears as something rationally explained. In the field of human behavior, insanity was madness to be disposed of by the snake pit or the gallows only a hundred years ago; today it is recognized as sickness, rationally understood and treatable. For Sigmund Freud, the most irrational has its rational explanation and the most nonsensical proposition its symbolic meaning. Why, of all things, should the innocent emotive expressions, expletives, pejoratives, epithets, four-letter words, and all the rest that delight the 
emotivists, not have their own rational, indeed logical, frame of reference? Once this is found the positivistic equation of emotive with unscientific would fall to the ground. Supposing that the emotive is the ethical, ethics would then become the science represented by the frame of reference in question. For the time being, the positivists hold that whenever an emotive situation or proposition is explained, what is explained is not the emotive aspect - for that by definition cannot be explainedbut the factual aspect. In all such cases, if the explanation is called ethics, "ethics" is reduced to psychology, sociology, and such.

The dilemma is based on the Humean version of the moral fallacy, the confusion of subject matter with method of analysis: the analyst of a fuzzy subject matter must use a fuzzy method. Of course, those who approach a "fuzzy" subject matter, such as emotive attitudes and the like, with a presupposition of fuzziness, that is, the conviction that by definition what they are about to explain is not really explainable, will not be very successful in their explanation. As a matter of fact, the more, by their mental agility, they should progress in their rational explanation of the subject, the more they will draw back and emphasize the inadequacy of their procedure. The more they succeed in their analysis, the more they will emphasize its "failure." Its actual failure will not faze them, for it will only confirm their premise that what they are trying to do cannot really be done.

This was the case with Hume, and it is the case with Stevenson. It explains the peculiarly tantalizing quality of his book. He is committed not to succeed, that is, not to make the emotive too well understood, for that would destroy the thesis of the positivists to which he is committed. He is also committed to explaining the rational part of emotive meaning, for failure here would mean failure of his method. But success here would be dangerously close to success in the concomitant emotive part, which must be avoided. Thus, wherever the semantic part of his method promises success, as in the explanation of "good" in the "second pattern," he hurries to point out the inadequacy of the concomitant dispositional part, which really is the one that counts, dealing, as it does with the non-rational aspect of emotive meaning, and hence with ethics, while the rational aspect is really of no significance for ethics at all. ${ }^{18}$

Stevenson's "first pattern" of analysis says that "This is good' means 'I approve of this: do so as well."'19 According to his "second pattern" of analysis, "'This is good' has the meaning of 'This has qualities or relations X, Y, Z...except that 'good' has as well a laudatory emotive meaning which permits it to express the speaker's approval, and tends to evoke the approval part of the hearer." ${ }^{20}$ The part before 'except' is the disposition part. Like Moore, Stevenson is very careful, almost cagey, not to call his "patterns" definitions or to clarify his terms. Consequently, he does not make clear whether and in what respects his theory is semantics or psychology, empirical or non-empirical, whether, for example, "good" and "X, Y, and Z," in the second pattern are empirical properties or logical predicates, whether the emotive meaning of "good" is a pragmatic feature of the predicate "good" or an empirical property of the utterance $g-o-o-d$, and so forth. In one place, however, he 
says that his theory is empirical. ${ }^{21}$ His book, characteristically, lacks a subject index, which adds to the difficulty of orientation. Stevenson does not commit the moral fallacy by the content of his theory, which clearly states the difference between moral and axiological value, just as does Hume. He commits it, like Hume, by his method and by flagrantly confusing subject matter with the analysis of it, especially when he applies an argument about psychology to psychologists. ${ }^{22}$

For anyone who values rational clarity, studied obscurity is frustrating. Combining both the moral and naturalistic fallacy with the endeavor to rationalize the Kantian opposition of "ought" and "is," and yet not doing so in order not to disturb the positivistic thesis, produces a mixture of semantics and psychology that puts ethics into a limbo between the rational and the irrational, the logical and the psychological, the naturalistic and the non-naturalistic, the positivist and the non-positivist. It also complicates the problem of value in three respects: (1) in accepting the positivistic thesis of the irrational character of ethical propositions, (2) in applying rational analysis to this irrationality, and (3) in aiming not at the rational explanation but at the deepening of this irrationality. Positivistic value theory has been called "one of the strangest aberrations ever to visit the mind of man." ${ }^{23}$ Trying to bring order into this "aberration" seems only to deepen the confusion.

As a result, Stevenson's system is complex without being rigorous, and of limited applicability. Its examples are trivial. Using his theory to analyze a complex moral situation, for example, the Crucifixion of Jesus, or to analyze a complicated ethical theory such as Søren Kierkegaard's, Kant's, or Plato's, or a work of moral fiction, such as Franz Kafka's Trial would be impossible. What Stevenson says about Plato's definition of justice is absurd. ${ }^{24}$ On some profound moral issues, Stevenson shows a peculiar blindness, as in his trite analysis of the conscientious objector. ${ }^{25}$ Stevenson shows that positivists need not shy away from values. He does not show that they can be profoundly sensitive to them. He successfully eliminates positivistic axiophobia, but he does not establish positivistic axiotherapy or positivistic axiology.

Stevenson's position is a step ahead in value theory in being an analysis of value language rather than of value experience, but it is tied down to the emotivist bias, which prevents it from developing all the possibilities inherent in linguistic analysis. His powerfully mistaken enterprise in ethics reminds us very much of Tycho Brahe's equally powerfully mistaken enterprise in astronomy, as developed in Johann Wolfgang von Goethe's comparison of Tycho Brahe and Johannes Kepler. ${ }^{26}$ The feature of emotive meaning in Stevenson's theory that would lend itself to strict analysis of moral phenomena, the semantic or logical one of meaning, is underplayed; and the feature that does not lend itself to such analysis, the emotive one, is overplayed. As a result, the whole theory must be said to be a failure. It does not solve the knotty Kantian problem of "ought" and "is." Not only does it never really come to grips with it, it studiously avoids doing so. While rational value theories, such as John Dewey's, cut the Kantian knot by a bold stroke (unable, to be sure, to tie the loose ends together again), Stevenson, in his endeavor to untie the knot care- 
fully, becomes ensnared in it and resolves the situation by declaring his predicament a virtue.

No satisfactory account of the ethical is possible as long as one finds its essential nature in irrationality. In the end, the presupposed-irreparable and unobjectionable, indeed, welcome - irrationality of the subject matter will infect the method of analysis applied to it, as if a psychiatrist began his analysis with the conviction that it is really better to be crazy than sane. If the positivistic thesis is correct, and if the ethical as such is irrational, then the positivistic conclusion is correct that as ethics it cannot be rationally analyzed, that such analysis becomes psychology, sociology, and the like. Then a science of ethics is impossible.

If, by contrast, a science of ethics, or even a rational account of it, is regarded as possible, then, to that extent, the ethical loses its irrational character and hence, according to the positivist, its nature as ethics.

What is not possible, on the positivist premise, is rationally to account for the irrational. Either this analysis succeeds and the subject matter is not ethical any more, or else it fails and the analysis was not rational enough. Then, to that extent, on the positivistic premise, it becomes ethics. Either the subject matter loses its ethical character and becomes fact, or the analysis loses its factual character and becomes ethics. In both cases an analysis of ethics is impossible. There can be no ethicists; there can only be either social scientists or moralists. ${ }^{27}$

\section{B. Semantic Analysis}

By semantic analysis of ethical or empirical value language, I mean an analysis in terms of the signs or symbols of this language and the referents, the denotata or designata, of these signs. This analysis is more detached from the empirical material than the pragmatic, taking into consideration not the speakers but what they say. But it is less detached than would be an interpretation of value language in terms of its own logical structure. For language regarded semantically is still part of the situation in which it occurs, even though this situation is now more highly stylized and abstracted, into a pattern of three relations, those between the thinker, the sign, and the referent. Thus, the arbitrariness of selecting situational elements, which attaches to pragmatic analysis, is eliminated. However, when the semiotic language is itself defined in terms of behavioristic psychology, this advantage disappears and the semiotic reverts to the first level. The question remains concerning the relevance of semantic analysis for the definition of the moral —or ethical—character of situational language, that is, the question of arbitrariness in defining the moral realms. This question cannot be solved on this level of analysis, and insofar as semantic analysis is second-level analysis, it suffers from the same shortcoming of definitory arbitrariness.

Semantics is a part of semiotics in general. A semiotic language on the third level that would solve this difficulty is possible. It would have to be a language of semiotic syntactics that would not refer to or analyze either the moral or the ethical 
language, but would serve as norm for it such that the empirical language would be subsumed under it. Suppose that a self-sufficient, coherent, and consistent semiotic system exists, accounting for the formal relations among signs. If it were possible to define a certain configuration within this system as the set of rules applicable to the moral realm, that is, as Ethics, and to analyze both the empirical language of moral situations and the ethical language, referring to it in terms of this system in such a way that not only each situation but also each term accounting for it could be assigned a definite place within the system, then the requirements of a third-level language of value would be fulfilled. This kind of language would be different from the semantic language of the second level in not referring to or analyzing the empirical language but serving as norm for it. The empirical language would be subsumed under it - split up, re-arranged, re-modeled in accordance with the systemic pattern, just as the concepts of empirical language are re-modeled and re-shaped (and all but disappear) in the language of science. In the semantic analysis of the second level the point of departure is the empirical language, which is interpreted; but its terms and relations, its pattern as a whole, is not disturbed thereby. In analysis of the third level, the point of departure is the third-level system itself, and the empirical language is nothing but raw material for it. The empirical language is all but broken up in the process, so that the result is unintelligible to anyone but the experts on the third-level language - which means, precisely, that empirical language has been left behind. The procedure to reach this point would be, first, to exhibit a definite system of semiotic syntactics, second, to define some of its axioms and definitions as those of ethics, and, third, to apply the system to moral reality and show that it accounts for the natural relationships of moral situations and for their character as moral. All this may be possible if semiotic syntactics is indeed as genuine and autonomous a realm of thought as its proponents suggest, comparable with, or even superior to, logic and mathematics. As long as the correlation of such a system with value language is not established, all that semantic analysis can do-and this is an important service-is to sharpen value language and by doing so sharpen the observation of moral phenomena. But it can neither stake out the realm of morality nor define it.

\section{Logical Analysis}

By logical analysis of ethical language we could mean two things, corresponding to the two levels just discussed. We could either mean analysis of value concepts or creation of value constructs. The first would be analysis of value language in terms of some selected fields of logic, the second normative application of the fundamental axioms and definitions of logic to ethical language. The first would be second-level analysis and arbitrary in its intra-logical selectiveness; the second would be thirdlevel systematization and definitory of value language. Here the difference between second-level and third-level analysis appears not only in the selectiveness of the phenomena in moral reality, but also in the selectiveness of the fields within the pattern applied, that is, within logic. When a systematic pattern is applied to a phe- 
nomenal realm, it is not sufficient that a limited field within that pattern is selected; the pattern in its fundamental axioms and definitions must have an affinity to the phenomena to which it is applied. The one advantage of applying the system is, precisely, that there is a system, and that its formal relationships can be used to order the otherwise unrelated events. The system must have systematic and empirical import. If merely a small section of the system were used, one that has no intrinsic connection with the whole system, the purpose of system construction would be defeated. The applicability of mathematics to nature rests, precisely, on the fact that the fundamental notion of mathematics, "number," can be given a spatio-temporal interpretation. Thus, if any system is to be applied to value phenomena there must be an affinity between the fundamental notions and relations of that system and the value realm, and not merely an affinity between some outlying regions of the system and some regions of ethics. The difference between second-level and third-level value analysis - between meaning analysis of empirical concepts and systematic normativity for such concepts-is thus a difference between the application of unessential and of essential configurations within the system applied. For logic, by second-level analysis would be meant analysis of first-level value language in terms of more or less arbitrarily selected sections of logic, and by third-level analysis, the subsumption of first-level and second-level language under the fundamental axioms and definitions of logic.

In this section the first shall be the concern, even though it cannot be discussed without reference to the second. In this section, interpretations are given of first-level value language in terms of some selected field or fields of logic, such as interpretations of value language in terms of a particular relation, say, the relation "better than, ${ }^{, 28}$ or in terms of moods or modalities, ${ }^{29}$ imperatives,${ }^{30}$ and the like. These are selective and hence arbitrary applications of logic to morality and not definitions of morality in terms of logic. Note that logical analysis deals with imperatives, but it is not itself imperative (the normative fallacy). Any number of different ethical systems could be established on other logical relations or moods. Indeed, the variety of such systems could be as large as the content of logic itself. Only the ingenuity of system builders could set the limits. Why not, for example, build an ethics on the modality of impossibility, using James's definition of the ethical as the path of greatest resistance? Or on logical subsumption, using C. D. Broad's and others' notion of fittingness? Or, on the relation of contradiction, using it as prototype for the ethic of the nihilist, or on that of contrariety, as prototype of the ethics of the reformer? Or, with Bertrand E. Jessup ${ }^{31}$ and others, why not use the notion of relation itself as prototype of a situational ethics? Such systems of ethics would be, and insofar as they have been written are, a great advance in ethical theory. An empirical theory that lends itself to such interpretation evinces its inherent systematic.

Such systems are still arbitrary, even though in a very limited sense, namely, within the system of logic; but using logic itself for the interpretation of ethical language cannot be called arbitrary. On the contrary, it seems the most natural of all interpretations. What is logic for if not the interpretation of language? The intra-sys- 
temic arbitrariness exists as long as it is not made systematically clear in which respect and on what grounds the relation, modality, or function selected had to be selected for reasons inherent in the system of logic and, indeed, the nature of ethics. Not only must the logical field selected be a central region of logic and not merely an outlying one, such as the imperative, it must also correspond to a central and not merely an arbitrary region of ethics. The ethical system based on A. P. Brogan's relation is meliorism, but meliorism is merely one kind of ethics among many. The logical relation serving as basis for a system of ethics should be universal enough to include all possible ethical systems rather than merely one. Again, an ethics based on imperatives accounts for only a narrow section of the moral realm. The same would be true of the kinds of ethics envisaged above.

In all, four kinds of arbitrariness are possible in combinations of logic and ethics, in three degrees from greatest arbitrariness to least arbitrariness, in the following order of combinations: (1) of outlying logical fields with outlying ethical fields, (2a) of outlying logical fields with central ethical fields, (2b) of central logical fields with outlying ethical fields, and (3) of central logical fields with central ethical fields. Only the last combination would represent the genuine logical system of ethics: a combination not of selected propositions or selected relations or selected moods or functions with selected moral phenomena and ethical categories, but a combination of logical fundamentals as such with the nature of good. Such combinations would be, for example, a definition of "good" in terms the notion of proportional function or of implication or of some other logical fundamental, such as class-membership, truth-value, or extension and intension. Such a combination of ethics and logic, if it could be brought about naturally and demonstrated as necessary, would constitute a third-level system that ought to fulfill my requirement for the ideal value language, namely, to account in its own terms for all value phenomena as well as all analyses of such phenomena. It ought to do so for the reason that the system would be co-extensive with logical language itself and thus able to account for everything for which this language itself can account.

In this respect, probably, the combination of logic and ethics is more powerful than the other combinations discussed on this level-the semiotic, epistemological, and mathematical. It is true for all these combinations as well that, unless the fundamentals of the system in question are joined with the fundamentals of ethics, the resulting theory is arbitrary, even though this arbitrariness is of a higher kind, an intra-systemic kind, concerning selections from within a system, and thus far less arbitrary than the arbitrariness of the first level, which roams over the whole empirical realm. The requirement of combining fundamentals with fundamentals may be objected to by saying that it is too severe and that there is no reason why a systematic ethics cannot be constructed out of any logical material, just as systematic sciences have been constructed out of any mathematical material, without bothering about how fundamental within mathematics the sections selected are. Any number of unrelated mathematical systems have been and are being used to account for natural phenomena. To mention a few, astronomy uses the calculus, differential and integral 
equations, and non-Euclidean spaces; electrical theory uses complex numbers; quantum theory uses the matrix calculus; thermodynamics uses the calculus of probability. All these patterns were selected more or less at random from the whole body of mathematics, with reference solely to the structure of the phenomena to be accounted for. Natural philosophy, it may be held, would never have become a science if it had concentrated on matching only the fundamentals of mathematics with the fundamentals of nature. For one thing, it is and was almost impossible to decide what these are.

It may be conceded that the development of natural science through the combination of mathematical frames of reference with natural phenomena has not consciously proceeded in the manner I demand for ethics. But it may just as well be held that it has. The original application of mathematics to natural phenomena that gave rise to modern science was the insight "that the essence of a material thing was its being res extensa" ${ }^{32}$ plus the algebraic expression of space in the analytic geometry of René Descartes. It came about after profound reflection on the fundamental nature of thought and on the essence of nature. The second step, Gottfried Wilhelm Leibniz's invention of the calculus, was preceded by equally profound philosophical reflection on the nature of thought and of reality. The same goes, though in a lesser degree and in a different direction, for Sir Isaac Newton, namely, restricting scientific research to the phenomenal world. Yet, for one who framed no hypotheses, Newton was remarkably metaphysical. Once these first steps were taken, the development of mathematics, both pure and applied, followed in the original direction. It is plausible that the present impasse of the natural sciences "at the threshold of metaphysics," ${ }^{33}$ to quote Otto Bruhlmann, points to the necessity of a new departure, a new delving of speculative thought into the metaphysical depths of symbolism - which may lead to new and entirely unexpected mathematical applications, as, for example, the application of number theory to the theory of material particles.

Granting the objection, there is one great difference between what, with Moore, we may call "ethics as a systematic science" 34 and the science of nature. In the science of nature it did not matter whether or not a frame of reference was arbitrarily selected or not, for experiment and observation checked the correctness of the theoretical results. There is no corresponding check in the science of ethics. This science has to arise by the strength of its own inner coherence. It has to carry its checks within itself. The situation is similar to that discussed by Kant for the science of metaphysics. As we have seen, the difference between the possibility of a science of nature and that of a science of metaphysics is, for Kant, that in the science of nature the understanding is constantly checked by sense intuition, whereas in the science of metaphysics reason must contain its own checks within itself. There is only one such check, based on the nature of thought itself, namely, contradiction. The task of Kant's transcendental dialectic was to show the checks within reason to consist in various kinds of contradiction. Our situation is similar, only turned in a positive rather than a negative direction. Mathematical natural science needs no 
special internal convincingness since it has an external one, confirmation by experience and experiment. But the science of ethics needs special internal convincingness, and thus requires stricter rules than the science of nature. Any arbitrary selection of frames of reference, whether from logic or semiotic, epistemology or mathematics, or from whatever other source, is inadequate for it. For this reason all languages of ethics on the second leve! are inadequate, no matter how elaborately they are or could be developed. They would always be affected by the lack of necessity, which only the combination of systematic fundamentals with ethical fundamentals can guarantee. Thus, a system of value on the third level must be inter-axiomatic, by which I mean it must join ethical with non-ethical axioms.

Out of this demand arises an important consequence. It is often argued against the possibility of a system of ethics that no agreement could ever be reached about it. But once such a system has the inner convincingness just described, required as its presupposition, there will be no doubt in anyone's mind that this is the system looked for, or at least one which most closely resembles the ideal under the circumstances. Agreement about it would be a concomitant of the system. Such agreement could not be expected to appear at once; as with all advances, even in the field of science, the system would be slow of acceptance. But its truth-in every sense of the word - would guarantee its eventual success. In this respect it would not differ from a scientific system. The skepticism of those who doubt any agreement about ethical systems on principle is therefore unfounded. It is justified for first- and second-level analysis of value language, but not for third-level construction, which is as certain in its way as is mathematics in its way. Unless it is as certain, it is not third-level construction. In this respect, John Locke and his contemporaries were right when they compared ethical to mathematical demonstrability.

The career of Moore's theory of value is a verification of this argument. Moore's theory combines a fundamental of logic, the nature of definition and conceptual analysis, with the very fundamental of ethical language, the term "good." Only a minute adjustment in Moore's theory ought to be necessary for it to become a third- level language of value. To be sure, like in a sensitive organ, such an adjustment will make the difference between failure and success. An historical parallel is again afforded by Kant and his generalization of Hume's argument on causality through adjustment and elaboration of Locke's notion of analytic and synthetic judgment. Kant was very conscious of what he was doing and that his adaptation of Locke's notion made all the difference between obscurity and clarity. For, as he tells us in the Prolegomena, the clear can be found in the obscure only if a new thinker has first hit on the solution himself, "by his own reflection." Then he finds the new "general and yet definite principles elsewhere, where one could not possibly have found them at first" because the previous author "did not know that such ideals lay at the basis of (his) observations." But once the way is shown, even "men who never think independently have the acuteness to discover everything, after it has been once shown them, in what was said long ago, although no one has been able to see it there before. ${ }^{.35}$ Another historical parallel is that between Gottlob Frege and Bertrand 
Russell, who found in Frege what no one, not even Frege himself, had seen there before. In the same way, it seems almost certain that in Moore's theory is hidden a key that will unlock the doors of a system of ethics. Such a system would be a logical theory of the third level. As it stands, Moore's theory is a logical analysis of empirical ethics on the second level. How it could be transformed to one of the third level will be seen in the next chapter.

Another philosophy, existentialism, which for many will not seem to belong here at all, appears to be as close to the solution of a systematic ethics as Moore's. It has made an even deeper, or at least a wider, impression. While the logical notion on which Moore bases his value theory is that of conceptual analysis, that on which the existentialists base theirs is the relation of class membership - which they deny. The logical tenet of the existentialist is expressed in Jean-Paul Sartre's motto "existence precedes essence," which can also be formulated as "the singular precedes the universal" - human individuals in the fullness of life itself, of their unique personal existence, are beyond any conceptualization - except their own. Thus a new logical relation of single-class membership is established, as strikingly developed in Kierkegaard's Either/Or and Sartre's $L$ 'Etre et le Neant. A formal axiology could be developed by working down, so to speak, from existentialist dialectic to the axiological relationship holding between a thing and its concept, or up from the second to the first. ${ }^{36}$

\section{Epistemological Analysis}

By epistemological analysis of value language I mean analysis in terms of the theory of knowledge. Such analysis would, like the logical and, in a different sense the semiotical, have its ground and justification in the nature of thought itself. It would be on the third level if it normatively applies to empirical language in its own systematic terms, that is, if it constitutes a complete, coherent, and consistent system in itself, and if certain axioms of this system are defined as those of ethics. Otherwise, if selected epistemological insights are used to interpret value phenomena and their linguistic analyses, it would be on the second level. An attempt at such a secondlevel analysis is C. I. Lewis's An Analysis of Knowledge and Valuation. This attempt cannot be said to have succeeded, not even in terms of the second level, for the selected epistemological categories developed in the earlier parts of the work are not applied consistently to the valuational categories in the last part. Rather, the last part is largely a first-level analysis of moral phenomena in terms of empirical concepts, that are only loosely connected, if at all, with the epistemological categories developed in the earlier parts. Lewis's work, similar to Stevenson's, stands halfway between first- and second-level analysis, but for different reasons. It is not third-level analysis, for it neither presents a system of epistemology nor analyzes value language and its phenomena in its own terms. It is, in the field of epistemology, as selective as are A. P. Brogan and R. M. Hare in the field of logic; and in its analysis of value language, it is less consistent than either. 
Kant's is a third-level analysis of this kind. It is so subjecrively, in the mind of Kant, as well as objectively, once we understand Kant. For Kant, the system of value is integrated with the system of science, based on the a priori of the unity of apperception. In the systems of science and of morality, a hierarchy is established. Descriptions of scientific and moral phenomena on the first level are given in Kant's Pre-Critical writings like his Anthropology, which "observes the actual behavior of human beings." ${ }^{37}$ The principles of these descriptions on the second level are developed in the Metaphysics of the Natural Sciences and the Metaphysics of Morals; and the principles of such metaphysics on the third level are given in the Critique of Pure Reason, the Critique of Practical Reason, and their satellites, the Prolegomena and Groundwork, respectively. For Kant the Metaphysics of Morals was to be to applied ethics what pure mathematics is to applied mathematics, ${ }^{38}$ so that applied ethics would be in the field of moral philosophy what applied mathematics, or natural science,$^{39}$ is in the field of natural philosophy ${ }^{40}$ Whether this Kantian scheme was successful is not the question here. Kant worked on it to the end of his life, and it is the only such science that exists in moral philosophy. Objectively, this system contains possibilities for the third-level epistemological construction of ethical systems; they are by no means exploited, but if they were, they would lead, precisely, to the logical dialectic of existentialism. In its transcendental employment, the unity of apperception not only creates the world of objects, it also creates its own transcendental self, a process Kant only hints at in the Critique. To this process of transcendental self-creation, the whole apparatus of the Critique could be applied, and the result would be a new and third-level ethics. The system of the schematized categories is a construction in the sense of this level. (Three of my graduate students at Yale University made valuable contributions to this subject-David C. Hay, Peter E. Pezzolo, and Brenda Jubin).

\section{E. Mathematical Analysis}

By mathematical analysis of value language we can understand two different things, either second-level analysis or third-level construction. There is no reason why the fundamental notions of mathematics should not be applicable to those of ethics as long as the metaphysical fallacy is avoided, that is, if mathematics is used in its qualitative rather than quantitative aspect. Alfred North Whitehead made a telling case for just this possibility in his essay, "Mathematics and the Good,"41 and G. E. Moore himself placed "good" alongside number. Whitehead shows the connection between patterns of organization and the nature of good, both based on the human faculty of conceptualization. This, to be sure, seems to be an application to value of logic, rather than of mathematics. Whitehead's long-range program for symbolic logic is precisely the system of value.

When in the distant future the subject has expanded, so as to examine patterns depending on connections other than those of space, number, and quantity 
- when this expansion has occurred, I suggest that Symbolic Logic, that is to say, the symbolic examination of patterns with the use of real variables, will become the foundation of aesthetics. From that stage it will proceed to conquer ethics and theology. ${ }^{42}$

But this study of patterns can also be called mathematics. "Mathematics is now being transformed into the intellectual analysis of types of patterns....Mathematics is the most powerful technique for the analysis of the relations of patterns." ${ }^{, 43}$ But there are more strictly mathematical possibilities of ethical systems. One could envisage, for example, an application of the calculus to the process of growth as described by John Dewey and Sartre or an application of combinatorial analysis to the methods of agreement and disagreement, ${ }^{44}$ or, especially (and here a most significant attempt has been made) the application of "the logic of relativity" to ethics. ${ }^{45}$ Ethics, if it is to be a system, is a "space" in the modern sense of the word, and this, certainly is a fundamental aspect of it as a science. ${ }^{46}$

The geometry of non-Euclidean spaces is definitely a fundamental aspect of mathematics. If Henry Lanz had combined ethics and mathematics, his book, In Quest of Morals, would be a solution of the problem of value language. But he failed, from my point of view, in two respects. First, he does not define the ethical realm in terms of the system of coordinates that he designs. Rather, he takes ethics in its traditional form and merely interprets its arbitrary empirical concepts and situations in terms of his system. He does not use his system, as well he could have, to define the realm of ethics; he does not use it on the third, but merely on the second level of value analysis. Secondly, his system is not really a mathematical system; it is only an interpretation of logic through the techniques of tensor analysis. This interpretation of logic is highly suggestive and may well constitute a significant contribution to the adjustment necessary to make logic applicable to ethics. His work is incoherent in a way similar to C. I. Lewis's. Lewis's epistemological categories are not as strictly systematic as Lanz's logical categories, and Lewis's application of his categories to moral language is not as strict as Lanz's application of his categories to that language. While Lewis's value analysis is largely on the first level, Lanz's is consistently on the second level. Although he does analyze first-level ethical language and moral situations in his own terms, Lanz fails to integrate his new view into a new Ethics.

Although Lanz's is the most ambitious undertaking so far in this field, he is by no means alone or divorced from ethical tradition. We can trace the geometrical analysis of value language back to Pythagoras, to Plato's divided line (not to mention the inscription over the Academy and his last, and lost, Lecture On The Good), to Aristotle's calculus of distributive and rectificatory justice, to Baruch Spinoza's Ethica More Geometrico Demonstrata, to John Locke's conviction of the equal demonstrability of mathematics and ethics, to Jeremy Bentham's calculus, to Francis Hutcheson's "Universal Canon to Compute the Morality of any Actions," ${ }^{47}$ and to Jacques Rueff, ${ }^{48}$ Henry Margenau, ${ }^{49}$ F. S. C. Northrop,${ }^{50}$ Bertha B. Friedmann, ${ }^{51}$ and 
Hermann Friedmann, ${ }^{52}$ to mention just a few in our own time. All these are only selective attempts and do not represent the best possible theory of mathematical ethics.

\section{Third Level: Systematic Value Language}

By systematic value language I mean a formal system of axiology that does not analyze value language but constructs it - by autonomously defining it in its own terms. It is a system that defines certain of its own axioms as those of ethics and thus creatively defines the realm of ethics. This third-level language is independent of empirical language and its uses. ${ }^{53}$ It applies its own terminology to this language, which serves as its raw material-just as descriptions of natural processes and their analyses serve as raw material for mathematical interpretation, even though mathematics itself is independent of the empirical material.

Enough was said in the preceding sections about the possible nature of such a language to understand that at least four such systems are possible on this level: the semiotic, the logical, the epistemological, and the mathematical. It may well be that one of these will ultimately turn out to be supreme and would thus constitute a fourth level of value analysis. For the time being, logical analysis seems to have the greatest chance of becoming a third-level system. This would mean that the terms, propositions, and relations of value language would find their systematic position through reference to the system of logic, and that ethics and logic would merge in a similar way as physics and geometry have merged in natural science. Such a development may have to await an expansion of logic, just as the corresponding development in physics presupposed the expansion in geometry from Euclidean to non-Euclidean spaces. Possibly the Nikolai Lobachevskys and Jánus Bolyais of logic have already done their work in the persons of Immanuel Kant, G. W. F. Hegel, Edmund Husserl, John Dewey, and Ernst Manheim ${ }^{54}$ as well as George Boole, Bertrand Russell, and Ludwig Wittgenstein. Logic covers the total realm of thought, and any one direction - even the mathematical-is an arbitrary selection from the whole field of possible logics..$^{55}$ One or some of these logics might, after what has been said, be used to elaborate the logical elements in ethical theories, particularly G. E. Moore's theory. Thus either, as Susanne Langer said, "ethically interested logicians will probably be the founders of scientific ethics," ${ }^{156}$ or, more likely, logically interested ethicists. (Note that physicists created physics, not mathematicians.) Once their work is done, the division between ethics and logic will not exist any more in the old sense, since no axiology will be possible without logic_-just as today no physics is possible without mathematics. At that time, traditional ethics - first- level empiricism and second-level conceptual analysis - will be of only historical interest.

No matter what final form the system of axiology takes, it will be fundamentally different from the lower levels of value analysis. First of all, it will not exhibit any more the features of arbitrariness that we found on the lower levels. If several such systems should appear on the third level, each would have to exhibit necessity 
in its own terms; otherwise, it would not be a third-level system. Conceivably, such different systems would deal with different but equally fundamental aspects of the moral and ethical realm, just as different kinds of analysis today account for different natural phenomena in relativity and quantum theory, but with the same necessity and the same fundamental significance for physics. Many such systems of axiology cannot be, for the requirements that such systems have to fulfill are extremely severe. Not only will each system have to be consistent in itself, it will also have to accord with the fundamental propositions of ethics. It will have to account for any ethical theory on any level of analysis whatsoever-Plato's and Nietzsche's, James's and Stevenson's, Hare's and Hilliard's, Bentham's and Moore's, Kant's, Wilbur M. Urban's, and Kierkegaard's. It will have to do so not only in a general but also in a specific way. It will in the same precise manner have to account for the moral phenomena themselves, including those mentioned at the beginning of this chapter.

This is not all. The formality and universality of the theory means that more will be contained in it than applicability merely to the moral realm and its languages. It will have to be a general theory of value, applicable to and normative for not only ethics, but all fields of value. For, as Susanne Langer indicates,

if there is to be a science of value, someone must formulate the basic conceptions which shall give rise to ethics, aesthetics, and possibly economics, all at one stroke. If 'value' really constitutes a definable field, then all these sciences are related....Probably the whole system, once it is discovered, will look no more like present-day theory of value than astronomy looks like its precursor, astrology. ${ }^{57}$

Thus, not only will the new system have to account for and interrelate all the phenomena and propositions of ethics, but also those of all the other disciplines that have to do with value, which seems to be the whole realm previously called Moral Philosophy and today called Social Science and the Humanities. And it will have to do so in the same precise manner that physics interrelates "mechanics and physicochemistry and electrodynamics...by one elaborate system." what a stop sign has to do with the sign "Lidice," and the love of God with the love of buttons or the price of a cow, will be answered, for definite correlations will exist between the realms of ethics, metaphysics, economics, and semiotics; and all these realms will be precisely defined.

If this is so, and if the new system will by its very nature include the norms not only for ethics but all the other value sciences, then its inherent logic, its systematic import, ought to lead to ever new empirical discoveries-its empirical import, in the fields of value reality, as ever new applications of the system to reality will be found. The system itself will develop more and more and eventually divide into pure and applied axiology. Pure axiologists, as today pure mathematicians and mathematical logicians, would concentrate on the development of the system as such, whereas applied axiologists would be the future social scientists-psychologists, sociologists, 
economists, political scientists, as well as the future ethicists, aestheticians, and metaphysicians, whose sciences will be, precisely, the application of the new system to their respective fields. ${ }^{59}$ Then, in the social sciences and the humanities, the same hierarchy of language levels will exist as does exists today in the natural sciences. On zero level will be the various social and moral situations, on the first-level will be empirical descriptions of value situations, on the second-level conceptual analysis of these descriptions, and on the third-level the autonomous system that defines the various realms of value in its own terms and functions for them as superstructure, in the same way that mathematics functions as superstructure for physics and other natural sciences. Just as today mathematics is the language of natural science, axiology will then be the language of value science.

This language will not spring forth ready-made from the head of a philosopher or scientist. Rather, for a long time to come, value languages will persist on all levels, in trial and error, and value theory will be in the same condition in which we find sciences such as biology today, existing on all levels of analysis, from first-level empirical description to third-level systematization, but without any (or with only loose) correlation of the various levels. Third-level analysis in biology is more advanced than it is in the social sciences, but it is by no means yet a completed and accepted system. Mathematically, it ranges all the way from primitive diagrammatic and geometric design to complex mathematical formulation and symbolic logic. ${ }^{60}$ Today's value theories do not have any systematically significant material interrelations, but they do have the formal interrelations traced and formulated in the five propositions previously delineated. Understanding the hierarchy of value languages, therefore, makes it possible to classify and analyze value theories and to assign to them a systematic position in the still unsystematic enterprise of valuation. This same hierarchy, through the axiological fallacies, also makes possible a critique of these theories. 